\title{
A Prospective Study to Investigate the Placement of Setup Skin Markings for Larger Breasted Women Undergoing External Beam Radiotherapy (RT) for Breast Cancer
}

Chris Osam Doudoo, Neill Roberts, Emmanuel Amankwaa Frempong, Clement Edusa, Kwamena Beecham,

Kofi Agyiri, Promise Ahiagbenyo, George Felix Acquah, Phillip Oppong Kyeremeh, Dominic Gadeka, Eric Abakuri, Michael Mordey, Anna Maria Anim- Sampong, Bismark Djan

Department of Radiation Oncology, Sweden Ghana Medical Centre, East- Legon Hills, Accra- Ghana

\section{ABSTRACT}

Background: The technique of placing all three skin marks (reference skin marks) on a single position during CT simulation for setup of patients undergoing conventional breast radiotherapy becomes a challenge when presented with larger breasted women (bra cup size $\geq$ D). A new way of using skin marks in setting these patients up has been developed where three skin marks are made on the patient (one on the sternum and two lateral skin marks more inferiorly beneath the breasts) for setup as against the departmental standard of using only a single skin mark on the sternum, and employing an SSD (Source to Skin Distance) technique.

This study therefore reviewed the placement of the skin markings for larger breasted women undergoing external beam radiotherapy for breast cancer by quantifying treatment field alignment errors and setup errors between the two different setup techniques.

Method: 36 patients were used in this study. Out of this number, 18 were setup using three reference skin marks and the remaining 18 were setup using one reference anterior skin mark. With an acceptable patient treatment field alignment error of 2 degrees, portal images (AP and lateral) of the different skin mark techniques were analysed for field alignment errors using an Iview GT system. More so, portal images (AP and lateral) of setup for both techniques were analysed for systematic $(\Sigma)$ and random $(\sigma)$ errors.

Results:The AP images of the single skin mark setup and the three skin mark setup yielded no significant difference as they recorded a $\mathrm{p}$ - value $(\mathrm{p}<0.05)$ of 0.089 and 0.110 respectively when compared to the treatment field alignment threshold error of 2 degrees. The lateral images of the three skin mark also yielded no significant difference as a $\mathrm{p}$ - value $(\mathrm{p}<0.05)$ of 0.091 was recorded. The lateral images of the single skin mark yielded a significant difference with a $\mathrm{p}$ - value $(\mathrm{p}<0.05)$ of 0.026 .

Secondly, mean comparisons of the field alignment errors between the two setup techniques yielded no significant difference in the AP images as a $\mathrm{p}$ - value $(\mathrm{p}<0.05)$ of 0.089 was detected. On the contrary, a $\mathrm{p}$ - value $(p<0.05)$ of 0.026 was recorded in the field alignment errors of the lateral images. This difference is significant.

Lastly, random errors were reduced in all directions (AP- anterior-posterior, SI- superior-inferior and LR- Leftright) in the three skin mark setup (4.5mm AP, $4.9 \mathrm{~mm}$ SI and $2.4 \mathrm{~mm} \mathrm{LR})$ as compared to the single skin mark setup ( $4.7 \mathrm{~mm}$ AP, $5.2 \mathrm{~mm}$ SI and 2.6mm LR). Systematic errors were also reduced in the three skin mark setup (1.7mm AP and $1.8 \mathrm{~mm} \mathrm{SI}$ ) compared to the single skin mark setup (2.0mm AP, $2.1 \mathrm{~mm} \mathrm{SI).} \mathrm{Systematic} \mathrm{errors} \mathrm{in}$ the LR direction on the other hand increased from $2.0 \mathrm{~mm}$ in the single skin mark to $2.2 \mathrm{~mm}$ in the three skin marks. 


\section{Conclusion}

For setup of larger breasted women undergoing external beam radiotherapy for breast cancer, the three skin mark setup technique is superior to the single skin mark setup technique.

Keywords : Skin Markings, Beam Radiotherapy, Breast Cancer, tumor, BMI, TPRP

\section{INTRODUCTION}

Breast cancer is the most frequently diagnosed cancer in women. It accounts for nearly one-third of cancers diagnosed in females. Most breast cancer cases are diagnosed in postmenopausal women, with an average age of around sixty years (Cancer facts and figures, 2017).

Detection of breast cancer at the early stages increases the cure rate up to almost 90\% (Cancer facts and figures, 2017). Hence, the constant efforts by organizations and medical outfits worldwide to create breast cancer awareness. The emphasis on early detection as well as improvement in imaging procedures has tremendously increased the incidence of patients presenting with non-invasive breast cancer and as a result has increased the percentage of breast conservative treatment, radiotherapy inclusive (Linder and Schiska, 2015)

Years of clinical studies have proven that breast conservation therapy offers the same cure rate as mastectomy and that adjuvant radiotherapy to the breast is now considered part of the standard care in breast conserving therapy (Veronesi et. al. 2002). In addition, results from randomized clinical trials in early stage breast cancers have shown improved local control in breast radiotherapy after breast conserving surgery (Fisher et.al. 2002).

Most early stage breast cancer patients receive radiotherapy as part of their treatment (Clarke et al., 2005). The reason behind breast conserving therapy is to give patients the same cure rate if treated with mastectomy and to leave the breast intact with an appearance and texture as close to what was there before (Radiology Info.org, 2016). The authors further explained that, the long-term complications following conservative surgery and radiation therapy for early stage breast cancers are low.

Radiotherapy for breast cancer patients (candidates for breast conserving therapy) requires rigid immobilization and accurate positioning. According to Lakosi et. al (2015), the standard treatment for women with early breast cancer following breast conserving surgery is radiation therapy in the supine position. Varga et. al (2009), further emphasized the advantage of supine setup as resulting in increased accuracy of setup repositioning.

Traditionally, because of the nature of the chest well, patients are made to lie supine on a breast board which is usually inclined at about an angle of 10-20 degrees in order for the chest wall to be parallel to the surface of the couch and to also bring the lateral and inferior part of the breast anteriorly, to help with the treatment setup. Skin marks or tattoos are also made in the same plane on the thoracic region and are aligned with laser lights (midline and lateral) during immobilization for the radiotherapy process (Dobbs, Barrett, Morris and Roques, 2009).

\section{METHODS AND MATERIAL}

\section{Method}

\section{Study Design}

This study is a research which investigates and compares two different setup techniques for a 
category of patients undergoing external beam radiotherapy. This study used a positivist paradigm which is one of the theoretical framework which influences the way knowledge is studied and interpreted (Mertens, 2005).

The positivist theoretical perspective aims at testing a theory or describing an experience through observation and measurement in order to predict and control the situation at hand (Dash, 2005). According to the author, it reflects a concept in which cause determines effect and perceives the world as being atomistic in nature where the world is made up of discrete, observable elements which interact in an observable and regular manner.

This paradigm allowed the researcher to follow a well-defined structure which does not allow for huge changes in variables as well as gave the researcher the platform to use objective mathematical and scientific tools in the analysis of the study (Creswell, 2003).

More so, the positivist experimental approach used by the researcher in gathering data provided the researcher with information which could be used to make further scientific assumptions as far as radiotherapy setup for larger breasted patients are concerned (Essays, UK, 2014).

This paradigm also helped the researcher to maintain minimal interaction during the study (Wilson, 2010).

Non-positivists on the other hand perceive this as impossible because human behavior comes naturally with emotional responses. Non- positivists believe that, although positivism encourages researchers to maintain minimal interaction during the study, there is no guarantee that this will occur at all times during studies (Cram, 2014). This according to nonpositivists confirms the inflexible nature of positivists.
In summary, the positivists' paradigm was chosen for this study because, it gave the researcher the opportunity to test a procedure in order to provide a basis for knowledge. It is objective, has a high level of precision, transparent and free from personal prejudices.

According to Creswell (2003), if the experimental process is followed and statistical analysis done in the right manner, this framework is always likely to produce a valid and reliable outcome.

\section{RESEARCH METHOD}

This study is a prospective cohort study and a quantitative approach was used to evaluate the treatment setup techniques for larger breasted patients (cup size $\geq$ D) undergoing breast radiotherapy. This study categorized one group (patients with one skin mark on the sternum and two more inferior ones) as the test group and the other with only one anterior skin mark on the sternum as the standard in my department for larger breasted patients. This approach helped the researcher to be objective in the employment of statistical models to attempt to answer the primary research question as well as explain what is observed (Steber, 2017).

In order for this approach to be effective, a pilot study was conducted in the department, prior to the commencement of the main study. The pilot study helped to determine whether there were any potential problems with the proposed method. Three participants (larger breasted patients) with various cup sizes of D and above, were recruited for the study. All participants met the inclusion criteria stated and they did not take part in the main study. The pilot study was conducted under the same test conditions as the study. The outcome of the pilot study was not included in the final analysis of this study. 


\section{Participants}

Participants selected for this study were all larger breasted patients (cup size $\geq$ D) who had been diagnosed of breast cancer and were due for radiotherapy treatment to the breast.

The procedure was explained to all the participants and their consent was obtained at the time of initial assessment. Thirty-four of the participants were clients who had been referred to the facility for treatment and two of them were 'walk ins' who came to the centre on their own. In addition to the researcher, there were two female staff who were trained through youtube videos on how to measure bra cup sizes of patients selected to be part of this study.

\section{Sample Size}

Devane, Begley and Clarke (2004) suggested that it is almost impossible to work with an entire population during a clinical study or trial though that would have been ideal. Calculation of a sample size therefore helps a researcher to bring to the fore a strong conclusion which can be generalized from a limited amount of information (Gotgay, 2010). The study recruited thirty- six (36) participants through the adoption of the sample size formula by Cochran (1963) as seen below.

$n=\frac{\left(Z_{\frac{\partial}{2}}\right)^{2} p(1-p)}{d^{2}}$

Where:

n: sample size

$\mathrm{p}$ : the proportion of intact breast cancer patients seen monthly at the SGMC out of the total number of cancer cases per year, $\mathrm{p}=10.7 \%$ (SGMC cancer registry, 2017).

$\mathrm{d}$ : margin of error, $10 \%$ was used instead of $5 \%$ due to the limited duration of the study. The $5 \%$ precision would have given a bigger minimum sample size which could not have been achieved within study duration. However, the $10 \%$ gave a minimum but a sufficient sample size needed for the study.

\section{$\mathrm{Z} \alpha / 2=1.96$ since $\alpha=5 \%$ at $95 \%$ Confidence Level} Inputting the above into equation (1), the minimum sample size for participants required for this study was given by

$n=\frac{(1.96)^{2} \times 0.107(1-0.107)}{(0.1)^{2}}=36.70687216$

Therefore, $n$ is approximately 36 .

Therefore, the final minimum sample size for the participants was thirty- six (36).

This formula was employed to achieve a number which represents the target population and also to achieve a clinical and statistical significant result (Gogtay, 2010).

\section{Inclusion Criteria}

- Larger breasted women (cup size $\geq$ D) who had been diagnosed with breast cancer.

- Larger breasted women (cup size $\geq \mathrm{D}$ ) who have been diagnosed with breast cancer with no age or status specifications

- Larger breasted women (cup size $\geq \mathrm{D}$ ) who have been diagnosed with breast cancer and were due for 3D conformal breast Radiotherapy

\section{Exclusion Criteria}

- Larger breasted men (cup size $\geq D$ ) who have been diagnosed with breast cancer

- $\quad$ Larger breasted women (cup size $\geq D$ ) who had been diagnosed with breast cancer but have had mastectomy.

- Larger breasted women (cup size $\geq \mathrm{D}$ ) who had been diagnosed with breast cancer but were not receiving 3D conformal Breast Radiotherapy 


\section{Method of Recruitment}

A non- probability sampling method (purposive sampling) was used in this study because of the deliberate choice of participants by the researcher. The researcher decided on what needed to be known and as such together with a team of trained staff set out to find people who fit the criteria by virtue of their gender, diagnosis and size of their breasts (Saunders, Lewis and Thornhill, 2012).

The type of purposive sampling used was a homogeneous sampling technique and according to Etikan, Musa and Alkassim (2016), the main goal of this technique is to focus on particular characteristics of a population that are of interest, like a group of people that are similar in terms of age, gender, background, occupation, clinical history to mention but a few. For example, larger breasted women with a bra cup size of D and above who were diagnosed of breast cancer were chosen for this study.

The homogenous non- probability sampling method (purposive sampling) used in this study significantly helped the researcher in producing the desired number of primary data to contribute to this study as the primary research question being addressed is specific to the characteristics of a particular group of people (larger breasted women diagnosed with breast cancer who were undergoing Radiotherapy) (Laerd.com, 2012)

\section{Procedure}

A sealed envelope system which consisted of shuffled opaque envelopes were used to conceal prior knowledge of treatment setup techniques from the researcher and the participants (Hewitt, Hahn, Torgersen, Watson and Bland, 2005). A double blinding system was therefore used to eliminate performance bias (Kim and Shin, 2014).
Thirty-six envelopes were numbered 1 to 36. Letters corresponding to the indicated treatment setup techniques ( $\mathbf{S}$ for a single skin mark and $\mathbf{T}$ for three skin marks) were then inserted into the envelopes equally (18 of $S$ and 18 of $T$ )

The researcher after explaining the procedure to the patient and consent signed, randomized the participants into the two setup arms by presenting each participant with shuffled envelopes for them to pick any of their choice. The researcher opened the envelopes in the presence of participants to determine which treatment setup technique would be used for each of them. This method helped in removing selection bias between the two groups (Juni, Altman and Egger, 2001).

Out of the total number of thirty-six (36) larger breasted patients (cup size $\geq D$ ), eighteen (18) of them were marked with a single reference anterior skin mark placed on the sternum only, which is the departmental standard for larger breasted patients during CT scanning for simulation. The remaining eighteen (18), were also marked with an anterior skin mark placed on the sternum and two lateral skin marks placed more inferiorly on the sides just beneath the breast during their CT simulation procedure.

To find the bra cup sizes of patients involved in this study, the band sizes of patients during the CT simulation procedure was measured and recorded. This was measured around the patients' body just beneath the breast as seen in figure 3 . After that, the bust size was also measured and recorded. The bust size was determined by measuring around the fullest part of the breast and the figure rounded up to the nearest inch. This can be seen in figure 2 .

The bra cup size was therefore calculated by subtracting the band size value from that of the bust size and viewing the result on the Bra size guide and 
converter in appendix 3 (Hanesbrands Incorporation, 2018 and Seize guide, 2017). This value was then recorded for all cup sizes D and above (D, E, F, G, H, I).
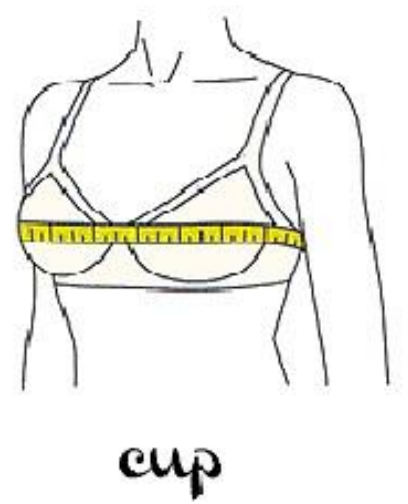

Fig. 1 Bust Size

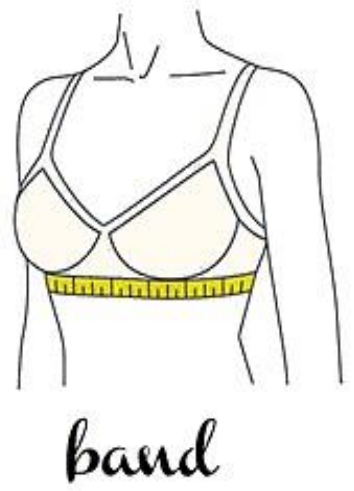

Fig. 2. Band Size

The bra cap measurement was taken by two female nursing staff in my facility who were trained through the watching of an online video session on bra cup measurement by the University of Iowa (University of Iowa Breast Health Centre, 2013). They rehearsed severally prior to the commencement of the study to perfect the performance of the procedure. The fact that they were females also made the patients feel very comfortable around them, during the procedure.

To prevent further bias, both nurses trained on the bra cap measurement were always in the room during the procedure to second check each other and okay the procedure. More so, measurements were taken with patients standing straight so as to be able to measure the circumference around the body
(Dundas, Atyeo and Cox, 2007). In addition, patients were politely asked to remove their shirts whilst still wearing brassiere so as to prevent inaccurate measurements in the case of thick clothing (Seize guide, 2017).

Lastly, the bra straps on the shoulders of the patients were lengthened by pulling it up and also pulling the bra band down halfway between the shoulder and the natural waist of the patient. This helped push the weight of the breast back unto the chest wall for effective measurement (University of Iowa Breast Health Centre, 2013).

\section{Data Analysis}

Data collected on the patients age, body mass index (BMI), stage of cancer and site of tumor (right or left) were recorded in Microsoft excel data collection sheet.

More importantly, patient treatment field alignment errors in relation to external skin marks (in degrees) provided by the Iview GT system for both AP and lateral images before correction were recorded in Microsoft excel for all patients from the first day of treatment to treatment completion. Patient treatment field alignment errors greater than two degrees (2o) were corrected by repositioning patients and verifying before treatment.

A total of 410 images were analysed for the single skin mark setup whereas a total of 320 images were analysed for the three skin mark setup. The numbers varied due to the different doses prescribed for each of the thirty-six participants used in this study as well as the frequency with which images were taken.

Data transferred from Microsoft excel were analysed using the Statistical Package software for the Social Sciences (SPSS), version 17.0. Cleaning of data was done by running frequencies of the variables. This checked inconsistently coded data. Inconsistently 
coded data were also double checked with raw data from our electronic system.

One sample t-test method was used to test for significant difference between the true mean, 20 (the default value per the protocol of the centre) and the comparison value/mean (the means obtained from each patient's alignment measurement over the treatment period) for both the control and the intervention arms. Independent sample t-test was used to compare the mean of the control arm (single marker) to the mean of the intervention arm (three markers).

Additionally, systematic and random set up errors were calculated for the anterior-posterior (AP), superior-inferior (SI) and left-right (LR) directions of the single marker setup and compared with that of the three marker setup.

Variables which were not normally distributed were transformed before analysis. A confidence interval of 95\% $(\mathrm{p}<0.05)$ was also used to show significant relationships.

Moreover, descriptive analysis was run for variables such as age (in years), BMI, stage of the disease and site of the disease (left or right).

\section{ETHICAL CONSIDERATIONS}

The proposed study was submitted to my line manager as well as the research and ethics committee of my facility for ethical approval.

After permission was granted, the nature and purpose of the study was first explained to participants who were recruited, irrespective of their race, colour or nationality.

None of the patients received an inferior form of treatment because setup was done appropriately and verified before treatment. Departmental protocols on imaging were applied to patients on both arms of research where the departmental threshold monitor unit was not exceeded.

Those who agreed to participate were given an informed consent form to sign before the bra cup sizes were measured. Participant information sheets were also provided to patients under the guidance of the researcher to help answer any questions pertaining to their role in the study.

Again, participants were made aware of the voluntary nature of the procedure and their right to withdraw at any point in time without explanation or penalty as well as assured of privacy and confidentiality.

\section{RESULTS AND DISCUSSION}

Descriptive analysis

Table 1. Demographic characteristics

\begin{tabular}{|c|c|c|}
\hline Variable & Frequency & Percentage (\%) \\
\hline Tumor Site & & \\
\hline Left & 22 & 61.1 \\
\hline Right & 14 & 38.9 \\
\hline Stage & & \\
\hline 1 & 16 & 44.4 \\
\hline 2 & 15 & 41.7 \\
\hline 3 & 5 & 13.9 \\
\hline 4 & 0 & 0 \\
\hline Age & 4 & 11.1 \\
\hline $30-40$ & 10 & 27.8 \\
\hline $41-50$ & 16 & 44.4 \\
\hline $51-60$ & 6 & 16.7 \\
\hline Above 60 & & \\
\hline BMI (kg/m $\left.{ }^{2}\right)$ & 0 & 0 \\
\hline Underweight & 4 & 11.1 \\
\hline Normal & 15 & 41.7 \\
\hline Overweight & 17 & 47.2 \\
\hline Obese & & \\
\hline
\end{tabular}


From the table above, 22 patients representing $61.1 \%$ of the population were left breasted whilst 14 patients representing $38.9 \%$ were right breasted.

Secondly, 16 patients representing $44.4 \%$ of the population and 15 patients representing $41.7 \%$ of the population were diagnosed of stage 1 and stage 2 breast cancers respectively, resulting in a total of $86.1 \%$. The rest of the population representing $13.9 \%$ were stage 3 breast cancers. None of the population was a stage 4 diagnosis.

Thirdly, 4 of the patient representing $11.1 \%$ of the population were aged between 30 - 40 years, whereas 10 patients representing $27.8 \%$ of the population were within the age range of 41-50 years. A large number of patients (16) representing $44.4 \%$ of the population were between the ages of $51-60$ years, whereas 6 patients representing $16.7 \%$ of the population were above the age of 60 . A total of $61.1 \%$ of the population were between the ages of 51-60 years and above 60 years.

Additionally, the reference values used for the body mass index (BMI) recorded for patients involved in this study were $18.5 \mathrm{~kg} / \mathrm{m}^{2}$ and less (Underweight), $18.5 \mathrm{~kg} / \mathrm{m}^{2}$ to $24.9 \mathrm{~kg} / \mathrm{m}^{2}$ (Normal weight), $25 \mathrm{~kg} / \mathrm{m}^{2}$ to $29.9 \mathrm{~kg} / \mathrm{m}^{2}$ (Overweight) and more than $30 \mathrm{~kg} / \mathrm{m}^{2}$ (Obese) (American Cancer society, 2018). There were no patients recorded for underweight. Out of a total of 36 patients, 4 representing $11.1 \%$ of the population were within the normal weight whereas 15 participants representing $41.7 \%$ were overweight. The highest number of the population (17) representing $47.2 \%$ were obese.

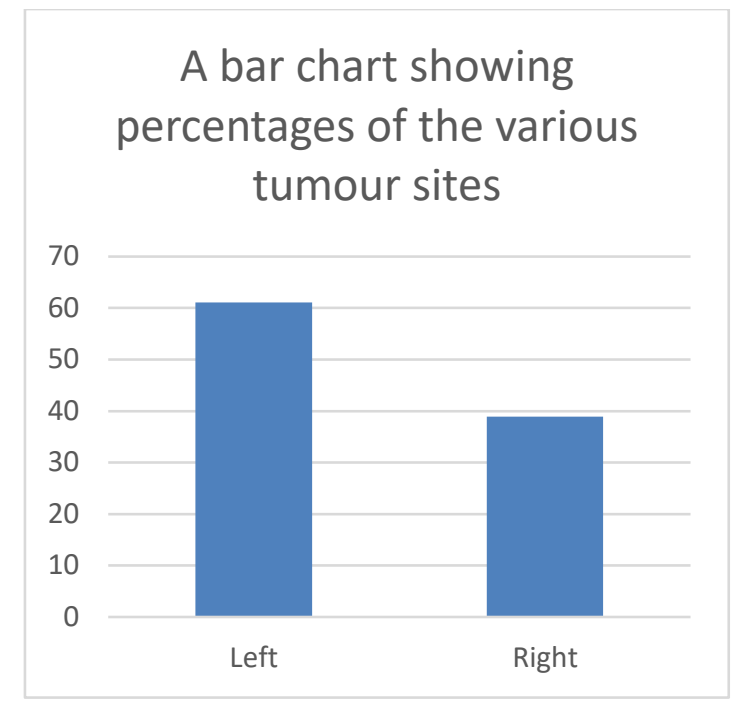

Fig. 3

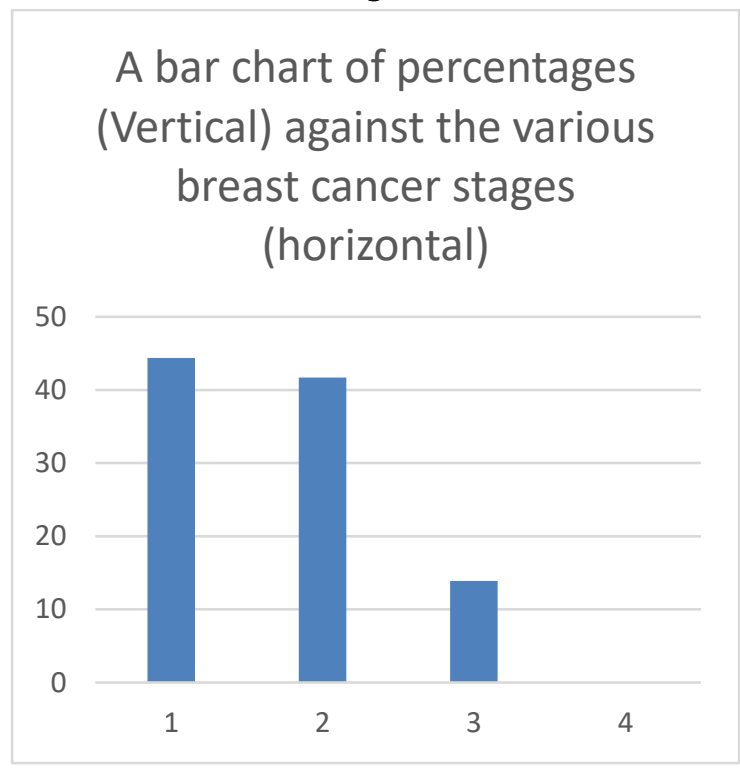

Fig. 4

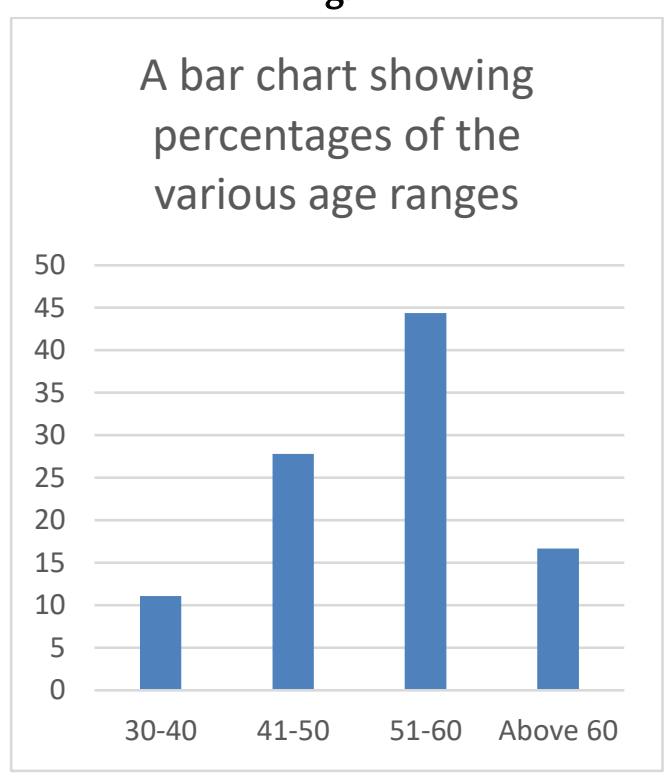

Fig. 5 


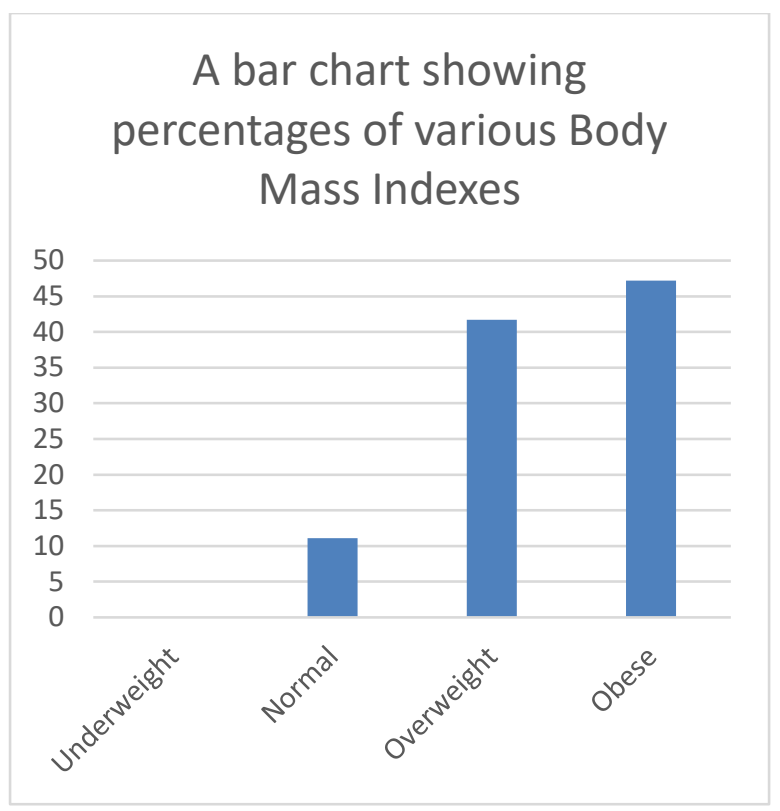

Fig. 6

The tables above show a bar graph of the descriptive analysis for the various demographic characteristics. Fig.1 shows the percentages (vertical axis) as against the tumour sites (horizontal axis) of the left and right, whereas Fig. 2 shows the percentages (vertical axis) as against the various breast cancer stages (horizontal axis) of 1 to 4 . Fig. 3 shows the percentages (vertical axis) as against the various age ranges (horizontal axis) of 30-40, 41-50, 51-60 and above 60 years. Finally, Fig. 4 shows the percentages (vertical axis) as against the various body mass indexes (horizontal axis) of underweight, normal, overweight and obese.

\section{A. SUMMARY OF MEAN COMPARISONS} BETWEEN BOTH ARMS (AP AND LATERAL FIELDS OF SINGLE AND TRIPPLE SKIN MARKS) AND TRUE MEAN.

Table 1. Anterior Images of Single Skin Mark Versus Departmental threshold

\begin{tabular}{|c|c|c|c|c|c|}
\hline Variable & Sample & $\begin{array}{c}\text { Mean } \pm \\
\text { SD }\end{array}$ & $\begin{array}{c}\text { MEAN } \\
\text { DIFFEREN } \\
\text { CE }\end{array}$ & T-test & $\begin{array}{c}\mathrm{p}^{-} \\
\text {value }\end{array}$ \\
\hline $\begin{array}{c}\text { Single } \\
\text { Mark }\end{array}$ & 18 & $\begin{array}{c}0.00 \pm \\
0.01\end{array}$ & 0.004 & 1.801 & 0.089 \\
\hline $\begin{array}{c}\text { Threshol } \\
\text { d }\end{array}$ & 18 & $\begin{array}{c}2.00 \pm \\
0.00\end{array}$ & & & \\
\hline
\end{tabular}

Table 2.

Table 2 compares the average displacements in terms of field alignment (in degrees) in the anterior images of the single skin mark technique in all 18 patients with the departmental threshold of 2 degrees.

In all 18 patients, an average field displacement error of 0 degrees and a standard deviation of 0.01 degrees were recorded. A $\mathrm{p}^{-}$value $(\mathrm{p}<0.05)$ of 0.089 was detected when compared to the accepted departmental field alignment threshold of 2 degrees.

Lateral Images of Single Skin Mark Versus Departmental threshold

\begin{tabular}{|c|c|c|c|c|c|}
\hline Variable & $\begin{array}{c}\text { Sam } \\
\text { ple }\end{array}$ & $\begin{array}{c}\text { Mean } \pm \\
\text { SD }\end{array}$ & $\begin{array}{c}\text { MEAN } \\
\text { DIFFER } \\
\text { ENCE }\end{array}$ & $\begin{array}{l}\mathrm{T}- \\
\text { test }\end{array}$ & $\begin{array}{c}\mathrm{p}- \\
\text { valu } \\
\mathrm{e}\end{array}$ \\
\hline $\begin{array}{l}\text { Single } \\
\text { Mark }\end{array}$ & 18 & $\begin{array}{l}0.02 \pm \\
0.037\end{array}$ & 0.021 & $\begin{array}{c}2.44 \\
8\end{array}$ & $\begin{array}{c}0.02 \\
6\end{array}$ \\
\hline $\begin{array}{c}\text { Threshol } \\
\text { d }\end{array}$ & 18 & $\begin{array}{c}2.00 \pm \\
0.00\end{array}$ & & & \\
\hline
\end{tabular}

Table. 3

Table 3 compares the average displacements of field alignment (in degrees) in the lateral images of the single skin mark technique in all 18 patients with the departmental threshold of 2 degrees. In all 18 patients, an average field displacement error of 0.02 degrees and a standard deviation of 0.037 degrees were recorded. A p- value $(\mathrm{p}<0.05)$ of 0.026 was detected when compared to the accepted departmental field alignment threshold of 2 degrees.

Anterior Images of three Skin Mark Versus

Departmental threshold

\begin{tabular}{|c|c|c|c|c|c|}
\hline Variable & $\begin{array}{c}\text { Sampl } \\
\text { e }\end{array}$ & Mean \pm SD & $\begin{array}{c}\text { MEAN } \\
\text { DIFFERE } \\
\text { NCE }\end{array}$ & $\begin{array}{c}\text { T- } \\
\text { test }\end{array}$ & $\begin{array}{c}\mathrm{p}^{-} \\
\text {value }\end{array}$ \\
\hline $\begin{array}{c}\text { Three } \\
\text { Skin }\end{array}$ & 18 & $0.00 \pm$ & 0.004 & 1.68 & 0.110 \\
Marks & & 0.011 & & 6 & \\
\hline Threshold & 18 & $2.00 \pm 0.00$ & & & \\
\hline
\end{tabular}


Table. 4

Table 4 compares the average displacement of field alignment (in degrees) in the anterior images of the three skin mark technique in all 18 patients with the departmental threshold of 2 degrees. An average field displacement error of 0.00 degrees and a standard deviation of 0.011 degrees were recorded. A p- value $(p<0.05)$ of 0.110 was detected when compared to the accepted departmental field alignment threshold of 2 degrees.

Lateral Images of Three Skin Mark Versus

Departmental threshold

\begin{tabular}{|c|c|c|c|c|c|}
\hline $\begin{array}{c}\text { Variabl } \\
\text { e }\end{array}$ & $\begin{array}{c}\text { Sam } \\
\text { ple }\end{array}$ & $\begin{array}{c}\text { Mean } \pm \\
\text { SD }\end{array}$ & $\begin{array}{c}\text { MEAN } \\
\text { DIFFER } \\
\text { ENCE }\end{array}$ & $\begin{array}{c}\text { T- } \\
\text { tes } \\
\text { t }\end{array}$ & $\begin{array}{c}\text { p- } \\
\text { valu } \\
\text { e }\end{array}$ \\
\hline $\begin{array}{c}\text { Three } \\
\text { Skin }\end{array}$ & 18 & $0.00 \pm$ & 0.005 & 1.7 & 0.09 \\
Marks & & 0.011 & & 91 & 1 \\
\hline $\begin{array}{c}\text { Thresho } \\
\text { ld }\end{array}$ & 18 & $2.00 \pm$ & & & \\
\hline
\end{tabular}

Table. 5

Table 5 compares the average displacements of field alignment (in degrees) in the lateral images of the three skin mark technique in all 18 patients with the departmental threshold of 2 degrees. An average field displacement error of 0.00 degrees and a standard deviation of 0.011 degrees were recorded. A p- value $(\mathrm{p}<0.05)$ of 0.091 was detected when compared to the accepted departmental field alignment threshold of 2 degrees.

\section{A. SUMMARY OF MEAN COMPARISONS BETWEEN CONTROL ARM (SINGLE MARKERS) AND INTERVENTION ARM (THREE MARKERS)}

\section{Table 6.}

A $\mathrm{p}$ - value $(\mathrm{p}<0.05)$ of 0.089 was realized when the anterior images of the three skin mark setup was compared to the anterior images of the single skin mark setup.

\begin{tabular}{|c|c|c|c|c|c|c|c|c|c|}
\hline & & \multicolumn{2}{|c|}{ MEAN \pm SD } & \multicolumn{2}{|c|}{$\begin{array}{c}\text { MEAN } \\
\text { DIFFEREN } \\
\text { CE }\end{array}$} & \multicolumn{2}{|c|}{ T-TEST } & \multicolumn{2}{|c|}{ P-VALUE } \\
\hline & $\begin{array}{l}\text { Sample( } \\
\text { n) }\end{array}$ & ANT & L.AT & ANT & LAT & $\begin{array}{l}\text { AN } \\
T\end{array}$ & $\begin{array}{l}\text { L.A } \\
\text { T }\end{array}$ & $\begin{array}{l}\text { AN } \\
T\end{array}$ & LAT \\
\hline SINGLE & 18 & $0.00 \pm$ & $0.02 \pm$ & 0.00 & 0.02 & & & & \\
\hline MARKS & & 0.01 & 0.037 & 4 & 1 & 1.80 & 2.4 & 0.08 & 0.02 \\
\hline $\begin{array}{l}\text { THREE } \\
\text { MARKS }\end{array}$ & 18 & $\begin{array}{l}0.00 \pm \\
0.011\end{array}$ & $\begin{array}{l}0.00 \pm \\
0.011\end{array}$ & $\begin{array}{l}0.00 \\
4\end{array}$ & $\begin{array}{l}0.00 \\
5\end{array}$ & & 5 & 9 & 6 \\
\hline
\end{tabular}

Additionally, a $\mathrm{p}$ - value $(\mathrm{p}<0.05)$ of 0.026 was realized when the lateral images of the three skin mark setup was compared to the lateral images of the single skin mark setup.

B. SUMMARY OF SYSTEMATIC AND RANDOM ERRORS FOR SINGLE AND THREE SKIN MARKS.

\begin{tabular}{|l|c|c|c|c|c|c|}
\hline & \multicolumn{2}{|c|}{ SINGLE SKIN } & \multicolumn{3}{c|}{ THREE SKIN } \\
& \multicolumn{3}{|c|}{ MARKER } & \multicolumn{3}{c|}{ MARK } \\
\hline ERRORS & AP & SI & LR & AP & SI(m & LR(m \\
& $(m$ & $(m$ & $(m$ & $(m$ & m) & m) \\
& m) & m) & m) & m) & & \\
\hline RANDOM & 4.7 & 5.2 & 2.6 & 4.5 & 4.9 & 2.4 \\
\hline $\begin{array}{c}\text { SYSTEMA } \\
\text { TIC }\end{array}$ & 2.0 & 2.1 & 2.0 & 1.7 & 1.8 & 2.2 \\
\hline
\end{tabular}

\section{Table 7}

Table 7 is a summary of mean systematic and random errors for single and three skin marker setups. The single marker recorded random errors of $4.7 \mathrm{~mm}$ in the Anterior-posterior plane (AP), $5.2 \mathrm{~mm}$ in the superior-inferior plane (SI) and $2.6 \mathrm{~mm}$ in the leftright plane (LR). The three skin marker setup on the other hand recorded random errors of $4.5 \mathrm{~mm}$ in the Anterior-posterior plane (AP), $4.9 \mathrm{~mm}$ in the superior-inferior plane (SI) and $2.4 \mathrm{~mm}$ in the leftright plane (LR).

More so, the single marker recorded systematic errors of $2.0 \mathrm{~mm}$ in the Anterior-posterior plane (AP), 2.1 $\mathrm{mm}$ in the superior-inferior plane (SI) and $2.0 \mathrm{~mm}$ in the left-right plane (LR) whereas the three skin marker setup recorded systematic errors of $1.7 \mathrm{~mm}$ in the anterior-posterior plane (AP), $1.8 \mathrm{~mm}$ in the superior-inferior plane (SI) and $2.2 \mathrm{~mm}$ in the leftright plane (LR). 


\section{DISCUSSION}

Accuracy, reproducibility and comfortability of larger breasted (cup size $\geq D$ ) cancer patients' during setup for CT simulation are critical throughout the treatment period as it goes a long way to affect treatment field alignment and outcome. (Hurkmans, Remeijer, Lebesque and Mijnheer, 2001).

Skin marks on fixed immovable points on the body has been used extensively for patient alignment before treatment in most radiotherapy centres and has been proven to be effective (Rathod, Munshi and Agarwal, 2012). In this study, patient treatment field alignment errors have been evaluated in thirty-six breast cancer patients. The novel part of this study is the evaluation of the placement of three skin marks in different planes on the skin of larger breasted (cup size $\geq$ D) women undergoing external beam radiotherapy of the breast. This new way of setting larger breasted patients up requires patients to lie supine on a breast board, with arms above head and aligned with lasers. The difference in this setup from the conventional setup is placing a skin mark on the sternum and two more skin marks inferiorly beneath the breast to help with lateral patient alignment. During treatment planning of this setup, the treatment planning reference point (TPRP) is placed on the skin mark on the sternum since it's the most stable point among the three skin marks. During treatment setup of this new technique, the two inferior skin marks are used for lateral patient alignment only. The patient is then moved to the skin mark on the sternum and the various shifts in all directions are made from the sternum to the isocentre. After that, images are taken to verify field alignment and patient setup before treatment.

The errors in setup and treatment field alignment of this new technique was compared to that of the standard treatment setup in the department where larger breasted (cup size $\geq$ D) patients are setup with only one skin mark preferably on the sternum and employing a source to skin distance (SSD) technique.

The first part of the results in this study focused on the descriptive analysis for the demographic characteristics. Bar graphs were also used to show differences among the demographic factors. Secondly, a summary of mean comparisons of the treatment field alignment errors of the anteriorposterior (AP) and lateral images were made between the single and three skin marks as against the true mean threshold of 2 degrees. Thirdly, a summary of mean comparisons of the field alignment errors of AP and lateral images were made between the single skin markers and the three skin markers. Additionally, systematic and random errors were calculated for the anterior-posterior (AP), superior-inferior (SI) and left-right (LR) directions of the single marker setup and compared with that of the three marker setup.

The demographic section of this study revealed a higher percentage (61.1\%) of the population diagnosed with cancer in the left breast as compared to that of the right $(38.9 \%)$ breast. This shows a higher prevalence of cancer in the left breast than in the right breast of patients who were involved in this study (Jardines, Goyal, Fischer, Weitzel and Royce, 2015). More so, $86.1 \%$ of the population were early staged breast cancers (Stage 1 and stage 2). No member of the population was a late stage diagnosis. A total of $61.1 \%$ of the population were between the ages of 51-60 years and above 60 years, suggesting that age is an important risk factor for breast cancer (Chen, Zhou, Tian, Meng and He, 2016). Lastly, the BMI revealed that, a total of $88.9 \%$ of the population of larger breasted patients involved in this study were within the overweight and obese range. This conclusion can be made because the patient selection criteria used for this study was partly randomized where participants were presented with shuffled envelopes containing letters corresponding to the 
indicated treatment setup techniques for them to pick any of their choice.

Wittmer, Pisansky, Kruse and Herman (2005) suggested the importance of treatment field alignment in terms of accurate patient setup during radiotherapy. The authors in this work reviewed a number of portal images, where uncertainties in field alignment was eventually disclosed. This resulted in the proposal of a pre-treatment imaging protocol to improve the accuracy and consistency of the field alignment. Jung et. al (2015), reiterated the importance of treatment field alignment and its role in ensuring accuracy and reproducibility in intact breast patients. According to the authors, it is necessary to confirm the field alignment errors through verification before patient treatment. It is in this regard that this current study sought to examine which of the skin mark placement techniques (single or three skin marks) is superior in ensuring accurate patient setup in terms of treatment field alignment during radiotherapy for larger breasted patients.

Murthy et al. (2008), in their study of setup error verification in breast, head and neck and pelvic patients undergoing external beam radiation therapy using electronic portal imaging recorded rotations for each treatment field to study the patient setup errors. The findings revealed that, in all the cases, $80 \%$ of the treatment field rotational errors were less than 1 degree, $95 \%$ of the errors were less than 2 degrees, and only $5 \%$ of the errors were within the range of 2 degrees to 3degrees. It was observed that the treatment field rotational differences were less than 3 degrees and any value greater than 3 degrees was termed significant. This is similar to the field alignment threshold used in this current study.

Langmack (2001) quantified patient displacement in a two dimension (2D) projection of a three dimension (3D) structure by image registration where portal image field edges were aligned with the reference image field boundary to determine rotational errors in treatment fields during radiotherapy. A rotational field error of less than 2 degrees similar to that of this study was used to emphasize the threshold for a good image registration algorithm. Remeijer et al. (2000) suggested that, when using a 2D registration method, the treatment field rotational errors should not be greater than 3 degrees. Plattard et al. (2000) evaluated the feasibility of a $2 \mathrm{D}$ registration for portal and simulator images to correct patient's position during radiotherapy. The accuracy of careful visual checking of treatment field rotational error in this study was evaluated at 2 degrees which is not out of place when compared to that used in this current study. Matsopoulos (2004) and Zheng and Ding (2017) evaluated a proposed methodology for patient set-up verification in the clinical environment and the inter-observer variability of image alignment during proton therapy respectively. A threshold of less than 1 degree was used by the former and a range from 0.6 to 1.3 degrees in rotational displacements were recorded by the latter.

First and foremost, when compared to the departmental threshold, it was noted that the AP images of the single skin mark setup detected a $\mathrm{p}^{-}$ value $(p<0.05)$ of 0.089 . This concludes that the difference in mean displacement errors in terms of field alignment between the anterior images of the single skin mark technique and the departmental threshold of 2 degrees is statistically insignificant. This is probably because of the use of an anterior skin mark for the setup which together with the lasers aligned patients very well in the AP plane.

Secondly, the lateral images of the single skin mark technique when compared with the departmental threshold detected a $\mathrm{p}$ - value $(\mathrm{p}<0.05)$ of 0.026 . This concludes that the difference in mean displacement of the treatment field alignment between the lateral images of the single skin mark setup technique and the departmental threshold is statistically significant. 
Thirdly, the treatment field alignment error of the AP images for the three skin mark technique recorded a $\mathrm{p}$ - value $(\mathrm{p}<0.05)$ of 0.110 when compared with the departmental threshold of 2 degrees. This concludes that the difference in mean displacement errors in terms of field alignment between the AP images of the three skin mark setup and the departmental threshold is statistically insignificant.

Additionally, the lateral images for the three skin mark technique detected a $\mathrm{p}$ - value $(\mathrm{p}<0.05)$ of 0.091 when compared to the departmental field alignment threshold of 2 degrees. This difference is statistically insignificant.

More so, mean comparisons of the field alignment errors between the control arm (single skin markers) and the intervention arm (three skin markers) yielded no significant difference in the AP images as a $\mathrm{p}$ - value $(\mathrm{p}<0.05)$ of 0.089 was detected.

On the contrary, a $\mathrm{p}^{-}$value $(\mathrm{p}<0.05)$ of 0.026 was recorded for the comparison between the field alignment errors of the lateral images of the single marker setup and the three marker setup. This difference is significant.

The results obtained by comparing field alignment errors (in AP and lateral images) of both the single skin mark setup and the three skin mark setup to the departmental threshold (2 degrees) as well as comparing the field alignment errors (in AP and lateral images) of the single skin mark setup to the three skin mark setup revealed significant differences only in the lateral images. This can be attributed to the absence of the lateral skin marks at the sides of the patient. Glassy, Glassy and Aldasouqi (2012) suggested that these lateral skin marks are used to align with the transverse lasers in order to level the patient to allow for field monitoring and precision of radiation delivery as well as reproducibility of tilt. More so, according to the International Atomic Energy Agency (IEAE) (2018), an accurate alignment setup system in a radiotherapy department should consist of at least three lasers to provide a sagittal line and two lateral crosses from the sides which can be used in conjunction with appropriately placed skin marks. Huppert, Jozsef, Dewyngaert and Formenti, (2011) also reiterated the importance of setting breast cancer patients up with skin marks at the sides together with an anterior skin mark on the sternum in order to establish a triangulation of skin marks for levelling the patient on a daily basis.

Furthermore, Rathod, Munshi and Agarwal (2012) suggested that skin marks or tattoos should be traditionally placed medially and on both lateral sides of the patient. Probst, Dodwell, Gray and Holmes (2006) revealed that, the combination of the two lateral skin marks or tattoos allows for a three-point localization of the initial isocenter of the treatment field, hence the need to always have them to help with treatment field and patient alignment.

This study also measured the systematic and random setup errors in the $\mathrm{X}, \mathrm{Y}, \mathrm{Z}$ plane. Systematic errors $(\Sigma)$ were calculated as the standard deviation of mean errors, calculated for each individual patient in the group. Random errors $(\sigma)$ on the other hand were calculated as the mean of individual random errors (CPL, 2011 and The Royal College of Radiologists, London, 2008).

Several works in the past have been conducted in this regard. Kirby et al. (2011) in their study to compare standard supine position in women undergoing whole-breast-radiotherapy (WBRT) in terms of feasibility and set-up errors, recorded systematic errors of $1.3 \mathrm{~mm} \mathrm{LR}, 1.5 \mathrm{~mm}$ SI, $1.8 \mathrm{~mm}$ AP and random errors of $2.8 \mathrm{~mm} \mathrm{LR}, 3.2 \mathrm{~mm}$ SI and $2.4 \mathrm{~mm}$ AP. Topolnjak et al. (2008) recorded systematic errors of $2.4 \mathrm{~mm} \mathrm{LR}, 2.3 \mathrm{~mm}$ SI and $1.5 \mathrm{~mm} \mathrm{AP}$ and random errors of $2.8 \mathrm{~mm} \mathrm{LR}, 4.1 \mathrm{~mm}$ SI and $3.6 \mathrm{~mm}$ AP in their study on breast conserving radiotherapy using external skin markers. White et al. (2007) 
investigated setup error reduction methods in accelerated partial breast irradiation (APBI) where systematic errors for skin-mark setup were $2.7 \mathrm{~mm} \mathrm{LR}$, $2.4 \mathrm{~mm} \mathrm{SI}$ and $1.7 \mathrm{~mm} \mathrm{AP}$ and random errors were $2.4 \mathrm{~mm} \mathrm{LR}, 2.9 \mathrm{~mm}$ SI and $2.2 \mathrm{~mm}$ AP.

The results of this current study were also similar to those recorded by Chang et al. (2012), Chung et al. (2015), Harris et al. (2016), Lozano et al. (2011), and Adamczyk, Piotrowski and Adamiak (2012), which were all based on setup error in relation to skin marks in early breast cancer patients using an imaging system with weekly IGRT.

Comparing the two setups in this study, systematic and random errors were reduced relatively in participants with three skin marks as compared to participants with only a single skin mark. Random errors were reduced from $4.7 \mathrm{~mm} \mathrm{AP,} 5.2 \mathrm{~mm} \mathrm{SI}$ and 2.6mm LR to $4.5 \mathrm{~mm} \mathrm{AP,} 4.9 \mathrm{~mm}$ SI and $2.4 \mathrm{~mm}$ LR. Systematic errors on the other hand were also reduced from $2.0 \mathrm{~mm}$ AP, $2.1 \mathrm{~mm}$ SI to $1.7 \mathrm{~mm} \mathrm{AP}$ and $1.8 \mathrm{~mm}$ SI. Systematic errors in the LR direction increased from $2.0 \mathrm{~mm}$ in the single skin mark to $2.2 \mathrm{~mm}$ in the three skin marks. The above suggests more reduced setup errors for the three skin mark setup as compared to the single skin mark setup.

The errors detected in this study were relatively high as compared to previous studies probably because this current study used only skin marks and lasers as well as a $2 \mathrm{D}$ imaging system, whereas most of the previous studies used skin marks together with surface imaging systems which have been shown to be of a higher precision (Alderliesten et al., 2012, Deantonio et al., 2011 and Padilla et al., 2014).The differences could also be attributed to the sample size, patient characteristics like breast size and weight of patients involved in this study as compared to previous studies. From this current study, it was observed that, even though the single skin mark technique was inferior when compared to the three skin mark technique, it reduced the number of skin marks that were made on the patient skin which is critical in departments where skin marks are not visible enough and as a result the use of needles have to be employed to create permanent skin marks (Rafi, Tunio, Hashimi and Ahmed, 2009). These permanent skin marks are known to have a psychological impact on breast cancer patients as a reminder of cancer treatment (Billingsley, 2001). One possible solution to this problem in current practice is the use of ultra violet (UV) tattoos that are not visible on the patient under normal conditions but highly visible during treatment settings (David, Castle and Mossi, 2006). According to Landeg et al. (2016), UV tattoos offer better setup accuracy compared to that of conventional dark ink and may improve patient experience of breast radiotherapy.

It was also observed that all patients regardless of the techniques used for setup recorded relatively high values of setup errors during the first few fractions of treatment but got stabilized due to departmental correction strategies factored into patient setup in the course of their treatment (Herman, 2005 and Mileusni, 2005). This could be as a result of patients being extremely nervous as well as radiation therapist not being used to individual patient setups during the first week of treatment. The setup errors also reflect how patients adapt to the environment with time from their first treatment fraction (Furuya et al., 2012).

Another observation made from this study was time for patient setup and verification during treatment. It was observed that a longer time was used to acquire an image and perform image registration for setup and verification in the single skin mark setup as compared to that of the three skin mark setup especially during the first few days of treatment. This resulted in patients having to lie on the couch for longer times, which is very critical for larger breasted patients because the longer they stay on the couch, 
the more likely they are to move (Essapen, Knowles, Norman and Tait, 2002).

\section{Limitations of the study}

The outcome of this study suggests that skin marks are important for patient treatment field alignment as well as setup errors. They do fade away with time (Cancer research, 2014) and as such have to be made permanent through the use of tattoos. Further studies need to be conducted in this area to suggest alternative ways to be used in order to have good skin marks which are non-invasive and can last throughout an entire treatment schedule.

More so, this work only concentrated on treatment field alignment errors and setup errors associated with skin marks in larger breasted patients. There are other clinical factors which may also affect treatment accuracy and reproducibility (Beltran, Krasin and Merchant, 2011) like immobilization devices and patient compliance with setup procedures (Pisani et al., 2000). Further investigations have to be done for other factors especially patient compliance with the two setup techniques described in this study.

\section{Implications for future practice and research}

The findings of this study although may be applicable locally, also suggests areas of future exploration.

The findings will help educate and also serve as a source of information for the radiotherapy staff and interns who are undergoing clinical rotations. It will also help update the departmental protocol on setup procedures for larger breasted patients (cup size $\geq D$ ) undergoing radiotherapy for breast cancer.

More so, findings from this study will improve patient setup and will also be a basis for future research and possible changes to breast cancer treatment setup.
Lastly, the findings of this study will be a source of information for other radiotherapy centres within and outside the country who have the same resources and are seeking to improve setup of larger breasted cancer patients in their facility.

\section{IV.CONCLUSION}

Field alignment errors in patients during a course of radiotherapy represents a systematic difference between patient simulation and treatment, hence setup techniques are critical especially in the setup of larger breasted patients during breast cancer irradiation.

Compared to the use of a single skin mark for setup of larger breasted patients, the outcome of the three skin mark setup is superior in terms of treatment field alignment for both the AP and lateral images with respect to the departmental threshold of 2 degrees.

Additionally, the three skin mark setup technique recorded relatively small systematic and random setup errors when compared to the single skin mark technique. It is important to note that these were shift values obtained before correction and as long as the departmental protocols on imaging frequency and threshold were followed, patient setup errors were reduced to the minimum especially in the three skin mark setup technique.

Finally, it is evident from this study, that the three skin mark setup technique is superior in terms of treatment field alignment as well as recorded relatively small patient setup errors when compared to the single skin marker setup technique.

\section{REFERENCES}

[1]. Acquah, G.F., Kyeremeh, P.O., Doudoo, C.O., Ahiagbenyo, P., Edusa, C. \& Beecham, K. (2017). Breast Dosimetry: A Phantom study 
between Tangential Wedge Fields and Multiple Open field-in-field 3D Conformal Forward Planning. International Journal of Scientific Research in Science and Technology, 3 (6), 2396011. Retrieved from https://www.researchgate.net/profile/George_A cquah/publication/318878230_Breast_Dosimetr y_A_Phantom_study_between_Tangential_We dge_Fields_and_Multiple_Open_field-infield_3D_Conformal_Forward_Planning/links/ 59830ac8a6fdccc3f53b1c56/Breast-Dosimetry-

A-Phantom-study-between-Tangential-

Wedge-Fields-and-Multiple-Open-field-infield-3D-Conformal-Forward-Planning.pdf

[2]. Adamczyk, M., Piotrowski, T. \& Adamiak, E. (2012). Evaluation of combining bony anatomy and soft tissue position correction strategies for IMRT prostate cancer patients. Reports of practical oncology and radiotherapy: journal of Polish Society of Radiation Oncology, 17(2), 104-9. doi:10.1016/j.rpor.2012.01.005

[3]. Alderliesten, T., Sonke, J., Betgen, A., Honnef, J., Van Vliet-Vroegindeweij, C. \& Remeijer, P. (2012). Application of 3D surface imaging in breast cancer radiotherapy. Journal of the International Society for Optical Engineering, 8316 (9). doi: 10.1117/12.911242

[4]. American Cancer society. (2018). Retrieved from: https://www.cancer.org/cancer/cancercauses/diet-physical-activity/body-weight-andcancer-risk/adult-bmi.html

[5]. Beltran C, Krasin, M. J, Merchant, T. E. (2011) Inter- and intra- fractional positional uncertainties in pediatric radiotherapy patients with brain and head and neck tumors. . International Journal of Radiation Oncology, Biology, Physics 79(4): 1266-1274. doi: 10.1016/j.ijrobp.2009.12.057.

[6]. Billingsley, J. (2001). "Breast-cancer Victims Bid Radiation Tattoos Goodbye." Retrieved from: https://consumer.healthday.com/cancerinformation-5/breast-cancer-news- $94 /$ some- breast-cancer-victims-bid-radiation-tattoosgoodbye-400312.html

[7]. Campana, F., Kirova, Y., M., Rosenwald, J., C., Dendale, R., Vilcoq, J., R., Dreyfus, H. \& Fourquet, A. (2005). Breast radiotherapy in the lateral decubitus position: A technique to prevent lung and heart irradiation. International Journal of Radiation Oncology, Biology, Physics, 61: 1348-1354. doi: http://dx.doi.org/10.1016/j.ijrobp.2004.08.051

[8]. Cancer facts and figures (2017). Retrieved from https://www.cancer.org/content/dam/cancerorg/research/cancer-facts-and-statistics/annualcancer-facts-and-figures/2017/cancer-factsand-figures-2017.pdf

[9]. Cancer Research, U.K. (2014). 'Invisible tattoos' could improve body confidence after breast cancer radiotherapy. Retrieved from: https://www.sciencedaily.com/releases/2014/11 /141102160008.htm

[10]. Chang, A., J., Zhao, H., Wahab, S,.H., Moore, K., Taylor, M., Zoberi, I., Powell, S.,N. \& Klein E., E. (2012). Video surface image guidance for external beam partial breast irradiation. Journal of Practical Radiotherapy and Oncology, 2(2):97-105. doi: 10.1016/j.prro.2011.06.013

[11]. Chen, H. L., Zhou, M. Q., Tian, W., Meng, K. X. \& He, H. F. (2016). Effect of Age on Breast Cancer Patient Prognoses: A Population-Based Study Using the SEER 18 Database. Retrieved from:

https://journals.plos.org/plosone/article?id=10.1 371/journal.pone.0165409

[12]. Chung, M. J., Lee, G. J., Suh, Y. J., Lee, H. C., Lee, S. W., Jeong, S., Lee, J. W., Kim, S. H., Kang, D. G., ... Lee, J. H. (2015). Setup Error and Effectiveness of Weekly Image-Guided Radiation Therapy of TomoDirect for Early Breast Cancer. Cancer research and treatment: Journal of Korean Cancer Association, 47(4), 774-80. doi: [10.4143/crt.2014.189] 
[13]. Clarke, M., Collins, R., Darby, S., Davies C, Elphinstone, P., Evans, E...........Wang,Y. (2005). Effects of radiotherapy and of differences in the extent of surgery for early breast cancer on local recurrence and 15-year survival: an overview of the randomized trials. Lancet, 366 (9503), 2087-2106. DOI: https://doi.org/10.1016/S0140-6736 (05)67887-7

[14]. Cochran, W.G. (1963) Sampling Technique. 2nd Edition, John Wiley and Sons Inc., New York.

[15]. College Physics Labs Mechanics (CPL), (2011). Measurement and error analysis. The University of North Carolina at Chapel Hill. Available at: http://www.webassign.net/question_assets/uncc olphysmechl1/measurements/manual.html 6/11/2018.

[16]. Coltman, C. E., Steele, J. R \& McGhee, D. M. (2017). Breast volume is affected by body mass index but not age. Journal of Ergonomics, 60 (11), 1576-1585. doi: 10.1080/00140139.2017.1330968

[17]. Cram (2014). Examine the Advantages and Disadvantages of Using Both Positivist and Interpretivist Methods of Research. Retrieved from: https://www.cram.com/essay/ExamineThe-Advantages-And-DisadvantagesOf/PKC9NAPK5C

[18]. Creswell, J. W. (2003). Research methods in education: Qualitative and quantitative and mixed methods approaches. London: SAGE Publications.

[19]. Dash, N.K. (2005). Retrieved from: http://www.celt.mmu.ac.uk/researchmethods/ Modules/Selection_of_methodology/index.php

[20]. David, J. E., Castle, S. K. B. \& Mossi, K. M. (2006). Localization Tattoos: An Alternative Method Using Fluorescent Inks. Radiation Therapist Journal, 15, (1). Retrieved from: http://www.people.vcu.edu/ kmmossi/downloa ds/Localization_Tattoos.pdf
[21]. Deantonio, L., Masini, L., Loi, G., Gambaro, G., Bolchini, C. \& Krengli, M. (2011). Detection of setup uncertainties with 3D surface registration system for conformal radiotherapy of breast cancer. Reports of Practical Oncology \& Radiotherapy, 16 (3). 77-81, doi: https://doi.org/10.1016/j.rpor.2011.02.003

[22]. Devane, D., Begley, C., M. \& Clarke M. (2004). How many do I need? Basic principles of sample size estimation. Journal of Advanced Nursing,47:297-302

[23]. Dobbs, J., Barrett, A., Morris, S., \& Roques, T (2009). Principles of Radiotherapy planning. In Practical Radiotherapy Planning (4th Edition). Abingdon, Oxon: Taylor \& Francis.

[24]. Dundas, K. L., Atyeo, J. \& Cox J. (2007). What is a large breast? Measuring and categorizing breast size for tangential breast radiation therapy. Journal of Medical Imaging and Radiation Oncology, 51(6), 589-593. Doi: https://doi.org/10.1111/j.1440-

1673.2007.01898.x

[25]. Essapen, S., Knowles, C., Norman, A. \& Tait, D. (2002). Accuracy of set-up of thoracic radiotherapy: prospective analysis of 24patients treated with radiotherapy for lung cancer. British Journal of Radiology; 75 (890):162-169. Retrieved from: https://www.birpublications.org/doi/full/10.125 9/bjr.75.890.750162

[26]. Essays, UK. (2013). Advantages and Disadvantages of Positivism. Retrieved from https://www.ukessays.com/essays/sociology/adv antages-disadvantages-positivism-

9924.php?vref=1

[27]. Etikan, I., Musa, S. A., \& Alkassim, R. S. (2016). Comparison of Convenience Sampling and Purposive Sampling. American Journal of Theoretical and Applied Statistics, 5, 1-4. doi: https://doi.org/10.11648/j.ajtas.20160501.11

[28]. Ferrari, A., Ivaldi, G., Leonardi, M.C., Rondi, E. \& Orecchia, R. (2009).Prone Breast 
Radiotherapy in a Patient with Early Stage Breast Cancer and a Large Pendulous Breast. Retrieved from: https://www.researchgate.net/publication/2674 9833_Prone_Breast_Radiotherapy_in_a_Patient _with_Early_Stage_Breast_Cancer_and_a_Larg e_Pendulous_Breast

[29]. Fisher, B.J., Bryant, J., Dignam, J., Anderson, S., Margolese, R. G., Deutsch, M.,.....Wolmark, N. (2002). Tamoxifen, radiation therapy, or both for the prevention of ipsilateral breast tumor recurrence after lumpectomy in women with invasive breast cancers of one centimeter or less. Journal of Clinical Oncology, 20(20):41414149. doi: 10.1200/JCO.2002.11.101.

[30]. Furuya, T., Sugimoto, S., Kurokawa, C., Ozawa, S., Karasawa, K. \& Sasai, K. (2012). The dosimetric impact of respiratory breast movement and daily setup error on tangential whole breast irradiation using conventional wedge, field-in-field and irregular surface compensator techniques. Journal of radiation research, 54(1), 157-65. doi: 10.1093/jrr/rrs064

[31]. Gotgay, N. J. (2010).Principles of sample size calculation. Indian journal of Opthamology, 58(6): 517-518. doi: 10.4103/0301-4738.71692

[32]. Glassy C. M., Glassy, M. S. \& Aldasouqi, S. (2012). Tattooing: medical uses and problems. Cleveland Clinic Journal of Medicine, 79: 76170. doi: https://doi.org/10.3949/ccjm.79a.12016

[33]. Hanesbrands Incorporation (2018). Calculating your bra size. Retrieved from: https://www.hanes.com/shop/hanes/BraFitCalc ulator

[34]. Harris, E. J., Mukesh, B., M., Donovan, E., M., Kirby, A., M., Haviland, J., S., Jena, R., P........Evans, M., P. (2016). A multi-centre study of the evidence for customized margins in photon breast boost radiotherapy. British Journal of Radiology, 89: 20150603, doi: https://doi.org/10.1259/bjr.20150603
[35]. Herman, G., M. (2005). Clinical Use of Electronic Portal Imaging. Seminars in Radiation Oncology Journal, 15 (3), 157-167, doi:

https://doi.org/10.1016/j.semradonc.2005.01.00 2

[36]. Hewitt, C., Hahn S., Torgerson, D. J, Watson J. \& Bland, J. M. (2005). Adequacy and reporting of allocation concealment: review of recent trials published in four general medical journals. British Medical Journal; 330:1057-8. doi: 10.1136/bmj.38413.576713.AE

[37]. Huang, S.Y., Boone, J. M., Yang, K., Packard, N. J., McKenney, S. E., Prionas, N. D., ... Yaffe, M. J. (2011). The characterization of breast anatomical metrics using dedicated breast CT. Medical Physics, 38(4), 2180-2191. http://doi.org/10.1118/1.3567147

[38]. Huppert, N., Jozsef, G., Dewyngaert, K., \& Formenti, S. C. (2011). The role of a prone setup in breast radiation therapy. Frontiers in oncology, 1, 31. doi:10.3389/fonc.2011.00031

[39]. Hurkmans, C., W., Remeijer, P., Lebesque, J., V. \& Mijnheer, B., J. (2001). Set-up verification using portal imaging: review of current clinical practice. Journal of Radiotherapy and Oncology, 58:105-120. doi: 10.1016/S01678140(00)00260-7

[40]. IAEA. (2018). Transition from 2-D Radiotherapy to 3-D Conformal and Intensity Modulated Radiotherapy. Retrieved from: https://wwwpub.iaea.org/MTCD/Publications/P DF/TE_1588_web.pdf

[41]. Jardines, L., Goyal, S., Fischer, P., Weitzel, J. \& Royce, M. (2015). Breast Cancer Overview: Risk Factors, Screening, Genetic Testing, and Prevention. Retrieved from: http://www.cancernetwork.com/cancermanagement/breast-cancer-overview-riskfactors-screening-genetic-testing-andprevention 
[42]. Jung, J. H, Cho, K.H., Moon, S. K. , Bae, S. H., Min, C. K. , Kim, E. S.......Yeo, S. (2015). Rotation Errors of Breast Cancer on 3D-CRT in TomoDirect. Progress in Medical Physics Journal, $\quad 26 \quad(1), \quad$ doi: http://dx.doi.org/10.14316/pmp.2015.26.1.6

[43]. Juni, P., Altman, D. G., \& Egger, M. (2001). Assessing the quality of controlled clinical trials. British Medical Journal, 323(7303), 4246. Available

https://www.ncbi.nlm.nih.gov/pmc/articles/PM C1120670/

[44]. Keller, L.M.M., Cohen, R.J., Sopka, D., Li, T., Li, L, Penny, A., Fowble, B, L \& Freedman, G.M. (2013). Practical radiation oncologyEffect of Bra Use during Radiotherapy for Large-Breasted Women: Acute Toxicity and Treated Heart and Lung Volumes. Retrieved from:

https://www.researchgate.net/publication/2357 86999_Effect_of_Bra_Use_during_Radiotherap y_for_Large-

Breasted_Women_Acute_Toxicity_and_Treate d_Heart_and_Lung_Volumes

[45]. Kim, J. \& Shin, W. (2014). How to Do Random Allocation (Randomization). Clinics in Orthopedic Surgery, 6(1), 103-109.doi: http://doi.org/10.4055/cios.2014.6.1.103

[46]. Kirby, A., M., Evans, P., Helyer, S., J., Donovan, E., Convery, H., \& Yarnold, J. (2011). A randomised trial of supine versus prone breast radiotherapy: Comparing set-up errors and respiratory motion. Journal of Radiotherapy and Oncology; 100: 221-6. doi: https://doi.org/10.1016/j.radonc.2010.11.005

[47]. Kirova, Y.M., Hijal, T., Campana, F., FournierBidoz, N., Stilhart, A., Dendale, R. \& Fourquet, A. (2014). Whole breast radiotherapy in the lateral decubitus position: A dosimetric and clinical solution to decrease the doses to the organs at risk (OAR). Radiotherapy and oncology, $110 \quad$ (3), 477-481. doi: https://doi.org/10.1016/j.radonc.2013.10.038

[48]. Laerd.com. Lund Research Limited. (2012). Retrieved from: http://dissertation.laerd.com/purposivesampling.php

[49]. Lakosi, F., Gulyban, A., Janvary, L., Simoni, S., B., Jansen, N., Seidel, L..... Coucke, P. (2015). Respiratory motion, anterior heart displacement and heart dosimetry: Comparison between prone $(\mathrm{Pr})$ and supine $(\mathrm{Su})$ whole breast irradiation. The journal of Pathology and Oncology Research, 21:1051-1058. doi: 10.1007/s12253-015-9932-9

[50]. Landeg, S. J., Kirby, A. M., Lee, S. F., Bartlett, F., Titmarsh, K., Donovan, E. ... McNair, H. A. (2016). A randomized control trial evaluating fluorescent ink versus dark ink tattoos for breast radiotherapy. The British journal of radiology, 89(1068), 20160288. doi: $10.1259 /$ bjr. 20160288

[51]. Langmack, K. (2001). Portal Imaging. British Journal of Radiology, 74(885), 789-804. doi: 10.1259/bjr.74.885.740789

[52]. Latimer, J.G, Beckham, W., West, M. \& Holloway, L. (2005). Support of large breasts during tangential irradiation using a microshell and minimizing the skin dose - a pilot study. Medical Dosimetry, 30: 31-5. doi: https://doi.org/10.1016/j.meddos.2004.10.006

[53]. Linder, J. M. \& Schiska, A. D. (2015). Progress in diagnosis of breast cancer: Advances in radiology technology. Asia-Pacific journal of oncology nursing, 2(3), 186-191. doi: 10.4103/2347-5625.158017

[54]. Lozano, E., M., Pérez, L., A., Torres, J., Carrascosa, C., Sanz, M., Mendicote, F. \& Gil, A. (2011). Correction of systematic set-up error in breast and head and neck irradiation through a no-action level (NAL) protocol. Journal of Clinical and Translational Oncology, 13(1):3442, doi: 10.1007/s12094-011-0614-0. 
[55]. Mahe, M. A., Classe, J. M., Dravet, F., Cussac, A. \& Cuilliere, J. C. (2002). Preliminary results for prone-position breast irradiation. International Journal of Radiation Oncology, Biology, Physics, 52: 156-160.

[56]. Matsopoulos, G., Asvestas, P., A., Delibasis, K., A., Kouloulias, V., Uzunoglu, N., Karaiskos, P. \& Sandilos, P. (2004). Registration of electronic portal images for patient set-up verification. Physics in Medicine and Biology Journal, 49(14):3279-89. doi:10.1088/00319155/49/14/018

[57]. Mertens, D. M. (2005). Research methods in education and psychology: Integrating diversity with quantitative approaches. (2nd ed.). Thousand Oaks: Sage

[58]. Mileusni, D. (2005).Verification and correction of geometrical uncertainties in conformal radiotherapy. International journal of Archive Oncology, 13(3-4):140-4.doi: 10.2298/AOO0503140M

[59]. Millsted, R. \& Frith, H. (2003). Being largebreasted: women negotiating embodiment. Women's Studies International Forum, 26(5), 455-465

[60]. Murthy, K. K., Al-Rahbi, Z., Sivakumar, S. S., Davis, C. A., Ravichandran, R., \& El Ghamrawy, K. (2008). Verification of setup errors in external beam radiation therapy using electronic portal imaging. Journal of medical physics, 33(2), 49-53. doi: 10.4103/09716203.41192

[61]. On Target (2008). Ensuring geometrical accuracy in radiotherapy. The Royal College of Radiologists, Society and college of radiographers, Institute of Physics and Engineering in medicine. Retrieved from https://www.rcr.ac.uk/system/files/publication/ field_publication_files/BFCO\%2808\%295_On_t arget.pdf

[62]. Padilla, L., Kang, H., Washington, M., Hasan, Y., Chmura, S. J., \& Al-Hallaq, H. (2014).
Assessment of inter-fractional variation of the breast surface following conventional patient positioning for whole-breast radiotherapy. Journal of applied clinical medical physics, 15(5), 4921. doi:10.1120/jacmp.v15i5.4921

[63]. Pisani, L., Lockman, D., Jaffray, D., Yan, D., Martinez, A. \& Wong, J. (2000). Setup error in radiotherapy: on-line correction using electronic kilovoltage and megavoltage radiographs. International Journal of Radiation Oncology, Biology, Physics, 47(3):825-839. doi: 10.1016/S0360-3016(00)00476-4

[64]. Plattard, D., Soret, M., Troccaz, J., Vassal, P., Jean-Yves, G., Champleboux, G., Artignan, X., \& Bolla, M. (2000). Patient Set-Up Using Portal Images: 2D/2D Image Registration Using Mutual Information, Computer Aided Surgery Journal, 5(4) 246-262. doi: $10.3109 / 10929080009148893$

[65]. Probst, H., Bragg, C., Dodwell, D., Green, D. \& Hart, J. (2013). A systematic review of methods to immobilize breast tissue during adjuvant breast irradiation. Available from Sheffield Hallam University Research Archive (SHURA) at: http://shura.shu.ac.uk/7467/

[66]. Probst, H., Dodwell, D., Gray, J., C. \& Holmes, M. (2006). An evaluation of the accuracy of semi-permanent skin marks for breast cancer irradiation. Radiography, 12:186-188. doi:101016/jradi20050700

[67]. Radiology Info.org (2016). Retrieved from https://www.radiologyinfo.org/en/info.cfm?pg= breast-cancer-therapy

[68]. Rafi, M., Tunio, M., A, Hashimi, A., H. \& Ahmed, Z. (2009). The South African Radiographer, 47(2). Retrieved from: https://pdfs.semanticscholar.org/371f/08b1214d f90096cc7adf1374da063f3d6749.pdf

[69]. Rathod, S., Munshi, A., \& Agarwal, J. (2012). Skin markings methods and guidelines: A reality in image guidance radiotherapy era. 
South Asian journal of cancer, 1(1), 27-29. doi: 10.4103/2278-330X.96502

[70]. Remeijer, P., Geerlof, E., Ploeger, L., Gilhuijs, K., Van Herk, M. \& Lebesque, J., V. (2000). 3-D Portal image analysis in clinical practice. An evaluation of 2-D and 3-D analysis techniques as applied to 30 prostate cancer patients. International Journal of Radiation Oncology, Biology, Physics, 15; 46 (5):1281-90. Retrieved from:

https://www.ncbi.nlm.nih.gov/pubmed/107256 42

[71]. Saunders, M., Lewis, P. \& Thornhill, A. (2012) "Research Methods for Business Students" 6th edition, Pearson Education Limited

[72]. Seizeguide (2017). Bra size guide and converter (BSGC). Retrieved from: http://www.sizeguide.net/bra-sizes.html

[73]. SGMC cancer registry, 2017.

[74]. Steber, C. (2017). Quantitative Research Design: Methods \& Appropriate Uses. Communications for Research. Retrieved from: https://www.cfrinc.net/cfrblog/quantitativeresearch-design

[75]. The Royal College of Radiologists, London (2008).The Royal College of Radiologists, Society and College of Radiographers, Institute of Physics and Engineering in Medicine: On Target: Ensuring Geometric Accuracy in Radiotherapy. Retrieved from: https://www.rcr.ac.uk/system/files/publication/ field_publication_files/BFCO\%2808\%295_On_t arget.pdf

[76]. Topolnjak, R., Van Vliet-Vroegindeweij, C., Sonke, J., Minkema, D., Rameijer, P., Nijkamp, J..... Rasch, C., (2008). Breast-conserving therapy: Radiotherapy margins for breast tumor bed boost. International Journal of Radiation Oncology, Biology, Physics, 72: 941-8, doi: https://doi.org/10.1016/j.ijrobp.2008.06.1924

[77]. University of Iowa Breast Health Centre. (2013). Bra Size: How to Properly Measure
Yourself [Video file]. Retrieved from https://www.youtube.com/watch?v=yIcwLBt4S 64.

[78]. Veldeman, L., De Gersem, W., Speleers, B., Truyens, B., Van Greveling, A., Van den Broecke, R. \& De Neve, W.(2012). Alternated prone and supine whole-breast irradiation using IMRT: Setup precision, respiratory movement and treatment time. International Journal of Radiation Oncology, Biology, Physics, 82(5):2055-2064. doi: 10.1016/j.jirobp.2010.10.070

[79]. Veronesi, U., Cascinelli, N., Mariani, L., Greco, M., Saccozzi, R., Luini, A.,.....Marubini, E. (2002). Twenty-year follow-up of a randomized study comparing breast-conserving surgery with radical mastectomy for early breast cancer. The New England Journal of Medicine, 347(16):1227-1232.

doi: 10.1056/NEJMoa020989.

[80]. White, E. A, Cho, J., Vallis, K., A, Sharpe, M., B., Lee, G., Blackburn, H.......Jaffray, D, A. (2007). Cone beam computed tomography guidance for setup of patients receiving accelerated partial breast irradiation. International Journal of Radiation Oncology, Biology, Physics, 68: 547-54, doi: https://doi.org/10.1016/j.ijrobp.2007.01.048

[81]. Wilson, J. (2010) "Essentials of Business Research: A Guide to Doing Your Research Project" SAGE Publications

[82]. Wittmer, M. H., Pisansky, T. M., Kruse, J. \& Herman, M. G. (2005). Patient-Specific Protocol to Reduce Radiation Therapy Setup Variation Using an Electronic Portal Imaging Device. Journal of Applied Clinical Medical Physics 6(4). doi: 10.1120/jacmp.v6i4.1954

[83]. Zheng, Y. \& Ding, X. (2017). Inter-Observer Variability of a Commercial Patient Positioning and Verification System in Proton Therapy. Journal of Radiology and Oncology, 1: 031-038. doi: 10.29328/journal.jro.1001004 


\section{APPENDIX 1}

\begin{tabular}{|c|c|c|c|c|c|c|c|c|c|c|}
\hline \multirow[t]{2}{*}{ Timeline } & \multicolumn{3}{|c|}{$2^{\text {nd }}$ Quarter 2018} & \multicolumn{3}{|c|}{$3^{\text {rd }}$ Quarter 2018} & \multicolumn{3}{|c|}{$4^{\text {th }}$ Quarter 2018} & \multirow{2}{*}{$\begin{array}{r}2019 \\
\text { Jan }\end{array}$} \\
\hline & April & May & June & July & August & Sep & Oct & Nov. & Dec & \\
\hline $\begin{array}{l}\text { Supervisor } \\
\text { allocation, } \\
\text { permission from } \\
\text { line manager and } \\
\text { timeline } \\
\text { negotiation. }\end{array}$ & & & & & & & & & & \\
\hline $\begin{array}{l}\text { Select and analyse } \\
\text { appropriate } \\
\text { research literature }\end{array}$ & & & & & & & & & & \\
\hline $\begin{array}{l}\text { Write up for } \\
\text { introduction, } \\
\text { review of } \\
\text { literature and } \\
\text { method (proposal) }\end{array}$ & & & & & & & & & & \\
\hline $\begin{array}{l}\text { Undertake pilot } \\
\text { study and prepare } \\
\text { for main study }\end{array}$ & & & & & & & & & & \\
\hline $\begin{array}{l}\text { Begin recruitment } \\
\text { process and gain } \\
\text { ethical approval }\end{array}$ & & & & & & & & & & \\
\hline $\begin{array}{l}\text { Undertake study } \\
\text { and collect data }\end{array}$ & & & & & & & & & & \\
\hline Data analysis & & & & & & & & & & \\
\hline $\begin{array}{l}\text { Result and } \\
\text { Conclusion } \\
\text { (Complete write } \\
\text { up) }\end{array}$ & & & & & & & & & & \\
\hline $\begin{array}{l}\text { Proofreading and } \\
\text { Submission }\end{array}$ & & & & & & & & & & \\
\hline
\end{tabular}


APPENDIX 2

Cup size calculator

\begin{tabular}{|c|c|}
\hline Bust size - Band size: & Cup size \\
\hline 1 & A \\
\hline 2 & B \\
\hline 3 & C \\
\hline 4 & D \\
\hline 5 & E \\
\hline 6 & F \\
\hline 7 & G \\
\hline 8 & H \\
\hline 9 & I \\
\hline 10 & J \\
\hline
\end{tabular}

Authors Details :

1. Chris Osam Doudoo (Main Author) - (Msc. Radiotherapy and Oncology)

Department of Radiation Oncology

Sweden Ghana Medical Centre

East- Legon Hills, Accra- Ghana

\section{Neill Roberts (Consultant Therapy \\ Radiographer)}

Faculty of Health \& Wellbeing

Leeds Cancer Centre

\section{Emmanuel Amankwaa Frempong (Radiation Oncologist)}

Department of Radiation Oncology
Sweden Ghana Medical Centre

East- Legon Hills, Accra- Ghana

\section{Clement Edusa (RADIATION ONCOLOGIST) \\ Department of Radiation Oncology \\ Sweden Ghana Medical Centre \\ East- Legon Hills, Accra- Ghana}

\section{Kwamena Beecham (Radiation Oncologist)}

Department of Radiation Oncology

Sweden Ghana Medical Centre

East- Legon Hills, Accra- Ghana

\section{Kofi Agyiri (Radiation Therapist)}

National Centre for Radiotherapy and Nuclear Medicine

Korle- Bu, Accra - Ghana.

\section{Promise Ahiagbenyo (Radiation Therapist)}

Department of Radiation Oncology

Sweden Ghana Medical Centre

East- Legon Hills, Accra- Ghana

\section{George Felix Acquah (Medical Physicist)}

Department of Radiation Oncology

Sweden Ghana Medical Centre

East- Legon Hills, Accra- Ghana

\section{Phillip Oppong Kyeremeh (Medical Physicist)}

Department of Radiation Oncology

Sweden Ghana Medical Centre

East- Legon Hills, Accra- Ghana

10. Dominic Gadeka (Diagnostic Radiographer)

Department of Radiation Oncology

Sweden Ghana Medical Centre

East- Legon Hills, Accra- Ghana 


\section{Eric Abakuri (Radiation Therapist)}

Department of Radiation Oncology

Sweden Ghana Medical Centre

East- Legon Hills, Accra- Ghana

\section{Michael Mordey (Radiation Therapist)}

Department of Radiation Oncology

Sweden Ghana Medical Centre

East- Legon Hills, Accra- Ghana

\section{Anna Maria Anim- Sampong (Radiation}

Therapist)

Department of Radiation Oncology

Sweden Ghana Medical Centre

East- Legon Hills, Accra- Ghana

\section{Bismark Djan}

Department of Radiation Oncology

Sweden Ghana Medical Centre

East- Legon Hills, Accra- Ghana
Cite this article as :

Chris Osam Doudoo, Neill Roberts, Emmanuel Amankwaa Frempong, Clement Edusa, Kwamena Beecham, Kofi Agyiri, Promise Ahiagbenyo, George Felix Acquah, Phillip Oppong Kyeremeh, Dominic Gadeka Eric Abakuri, Michael Mordey, Anna Maria Anim, Bismark Djan, "A Prospective Study to Investigate the Placement of Setup Skin Markings for Larger Breasted Women Undergoing External Beam Radiotherapy (RT) for Breast Cancer ", International Journal of Scientific Research in Science and Technology (IJSRST), Online ISSN : 2395-602X, Print ISSN : 2395-6011, Volume 6 Issue 2, pp. 99-122, MarchApril 2019. Available at doi : https://doi.org/10.32628/IJSRST19622 Journal URL : http://ijsrst.com/IJSRST19622 